\title{
65 Yaş Üstü Kadınlarda Jinekolojik Sorunlar
}

\author{
Huri GÜVEY 间 $^{1}$
}

\begin{abstract}
ÖZ
Son yıllarda artan yaşlı hasta popülasyonu nedeniyle jinekoloji birimlerinde bu hasta grubuyla daha sık karşılaşılmaktadır. Altmış beş yaş üstündeki hastalar geriartrik popülasyon olarak isimlendirilmektedir. Geriartrik yaş grubunda reprodüktif dönemde ortaya çıkan jinekolojik problemlerin çoğu ortadan kalkmaktadır. Hipoöstrojenemiye bağlı sorunlar ve yaşla birlikte artan jinekolojik maligniteler bu yaş grubunda ivme kazanmaktadır. Vulvovajinal atrofi ve vulvar distrofiler, genital prolapsus, postmenapozal kanama, mesane fonksiyonlarında değişiklikler, osteoporoz ve genital kanserler sıklıkla bu yaş grubunda karşımıza çıkmaktadır. Jinekolojik kanserlerin sıklığı ve mortalitesi de yaşla artış göstermektedir. Postmenapozal kanama endometrium kanseri belirtisi olabildiğinden dikkatle değerlendirilmeli ve mutlaka endometrial örnekleme yapılmalıdır. Pelvik organ prolapsusu ve üriner inkontinans pelvik taban kaslarının relaksasyonuna bağlı gelişmekte ve yaşam kalitesini olumsuz etkilemektedir. Vulvar distrofiler de genellikle kaşıntıyla ortaya çıkan ve çeşitli histolojik tiplere ayrılan bir hastalıktır. Osteoporoz kırık geliştiğinde yaşam kalitesini önemli derecede etkileyen morbidite ve mortalite sebebi olmaktadır. Jinekolojik şikayeti bulunan geriatrik yaş grubundaki hastalarda bu yaş grubuna spesifik problemlerin akılda tutulması ile uygun tanı ve tedavi yaklaşım daha kolay belirlenebilir.
\end{abstract}

Anahtar Kelimeler: Yaşlılar; jinekolojik hastalıklar; genital neoplaziler; atrofi.

\section{Gynecologic Problems in Women Over 65 Years of Age}

\begin{abstract}
Due to increase in elderly population in recent years, we encounter more frequently with this patient group in gynecology departments. Patients older than 65 age years are named geriatric population. Most of the gynecologic problems emerging in reproductive period disappear in geriatric age. Issues due to hypoestrogenemic and gynecologic malignancies increasing with age, spurs in this age group. Vulvovaginal atrophy and vulvar dystrophy, genital prolapse, postmenopausal bleeding, disturbances in bladder functions, osteoporosis and genital cancers are common in this age group. Frequency and mortality of gynecologic cancers increases with age. Postmenopausal bleeding should be evaluated carefully because this could be a symptom of endometrial cancer and these patients should be applied endometrial sampling. Pelvic organ prolapse and urinary incontinence develops due to pelvic floor muscle relaxation and effects quality of life negatively. Vulvar dystrophies are commonly pruritic diseases and have various histologic types. Osteoporosis also effects quality of life highly and leads morbidity and mortality when caused fractures. Keeping in mind the age specific problems in geriatric patients who had gynecologic complaint, appropriate diagnose and therapeutic interventions could be established.
\end{abstract}

Keywords: Geriatrics; gynecologic diseases; genital neoplasms; atrophy.

\section{GÍRIŞ}

Günümüzde değişen dünya koşullarının daha iyi ve konforlu bir yaşam getirmesine bağlı olarak beklenen yaşam süresi artmıştır ve bunun sonucu olarak da yaşlı popülasyonunda eskiye nazaran çoğalma görülmektedir. Bu durumda geriatrik popülasyonun sorunlarına yoğunlaşmak ve bakımı konusu üzerinde durmayı gerektirmektedir. Jinekoloji polikliniklerinde yaşlı hasta grubunu daha çok görmekteyiz. Yaşlı olarak sınıflandıracağımız popülasyon için yaş

1 Düzce Üniversitesi, Tıp Fakültesi, Kadın Hastalıkları ve Doğum A.D., Düzce, Türkiye 
sınırını 65 olarak değerlendirdiğimizde batı toplumlarında $\% 15$ oranında yaşlı insanlarla karşılaşmaktayız. Yaşlanma ile ortaya çıkan hipoöstrojenemiye bağlı doku değişiklikleri genitoüriner organların yapı ve fonksiyonlarını olumsuz şekilde etkiler (1).

$\mathrm{Bu}$ derlemenin amacı diğer yaş gruplarında daha az karşılaşılan özellikle yaşı kadınları etkileyen jinekolojik problemler olan vulvovajinal atrofi ve vulvar distrofiler, genital prolapsus, postmenapozal kanama, mesane fonksiyonlarında değişiklikler, osteoporoz ve genital kanserlerle ilgili güncel bilgileri gözden geçirmektir. $\mathrm{Bu}$ amaçla Pubmed, EMBASE, EBSCOhost, ULAKBİM veri tabanları "geriatrik hasta bakımı", "geriatrik hastalarda jinekolojik hastalıklar", "geriatrik kadınlar ve jinekolojik maligniteler”, “geriatrik kadınlar ve üriner inkontinans", "geriatrik kadınlar ve pelvik organ prolapsusu”, “üriner inkontinans”, “osteoporoz”, "postmenapozal kanama”, "vulvar distrofier”, "vulvovajinal atrofi" anahtar kelimeler kullanılarak taratılan literatürler değerlendirilmeye alınmıştır.

\section{Genital kanserler}

İlerleyen yaş kanser oranlarının artışıyla da ilişkilidir. 65 yaşından büyük olan \%60 yeni tanı konmuş kanser hastası olduğu \%70'inin de kanser nedeniyle öldüğü belirtilmektedir (2). Yaşla birlikte jinekolojik kanserler de artış göstermektedir. Over kanseri tanısı için ortanca yaş 63 'tür ve vakaların \%40,8'i 65 yaş ve daha üzeridir. İleri yaşta tanı alan vakaların yarısı 75 yaşından büyüktür (3). Endometrium kanseri olan hastaların \%40’1 65 yaşından sonra tanı almıştır ve 75 yaş üstü hastaların \%43'ü tanı anında ileri evrede olacaktır (4).

\section{Endometrium kanseri}

Amerikan Kanser Cemiyeti 2013 yılında \%6 yeni endometrium kanseri vakası tespit edildiğini bildirmiştir (5). Duman ve arkadaşlarının (6) yaptığ 1 çalışmada malignitesi olan 65 yaş üstü kadınların \%49'unda endometrium kanseri tespit edilmiştir. Türkiye'de en sık görülen 4. kanserdir (7). Hastaların \%75'ine postmenapozal dönemde tanı konur. Obezite, nulliparite, geç menapoz, hipertyansiyon ve diyabet risk faktörleri arasında yer alır. Genellikle vajinal kanama ile belirti verir. Dilatasyon ve küretaj yapılarak patoloji alınarak tanı konur. En sık görülen tipi endometrioid adenokarsinomdur (8). Primer tedavisi cerrahidir. Radyoterapi lokal kontrolü sağlamakta önemlidir. Kemoterapi ise yüksek riskli ve ileri evre olgularda ön plana çıkmaktadır (9).

\section{Serviks kanseri}

Yaş ilerledikçe riski artan jinekolojik kanserlerdendir. Tüm kadın kanserlerinin \%10'undan sorumludur. Düzenli takip ve tarama ile risk \%80 azalmaktadır (10). En önemli risk faktörleri arasında HPV infeksiyonu, erken yaşta cinsellik, çok partnerli ilişki, çok doğum yapmış olmak, immün supresyon, sigara kullanımı, düşük sosyoekonomik düzey yer almaktadır (8). Çoğunlukla ilişki sonrası kanama, kötü kokulu akıntı ve ülserasyonlarla belirti verir. Kesin tanı için kolposkopi ve serviks biyopsisi uygulanır. Ülkemizin birçok yerinde yaygın olarak uygulamaya giren ulusal serviks kanseri tarama programları ile erken evrede tanı konulup tedavi imkânı sağlanmaktadır. En sık yassı hücreli tip ikinci olarak da adenokarsinom tipi görülür. Tedavi seçenekleri hastalığın evresine göre değişmektedir (11).

\section{Over kanseri}

Over kanseri ABD verilerine göre kadınlarda yedinci sırada görülen bir kanserdir. Bununla birlikte kadınlarda tüm kanserler içinde ölüm nedeni olarak beşinci sıradadır (12). En öldürücü jinekolojik kanserdir. Over kanserleri içerisinde ise yaklaşık \%90'1 epitelyal kaynaklıdır (13). Tanıda olguların \%70'i ileri evrede yakalanmaktadır. En yüksek görülme sıklığı ise 75-77 yaş grubundadır. Erken menarş, geç menopoz, infertilite, ailesel yatkınlık, kalıtsal over veya meme kanseri sendromu, endometriozis, nulliparite önemli risk faktörleridir. Prognozu hastalığın evresi ve tümörün tipine göre değişiklik göstermektedir (11).

\section{Postmenapozal kanama}

Postmenapozal kanama (PMK) 1 yıllık amenoreden sonra gelişen vajinal kanamadır ve genel popülasyonda \%10 gibi yüksek insidansla karşımıza çıkan yaygın bir medikal problemdir. Jinekolojik malignitelere eşlik edebilmesinden dolayı PMK'nın sebebinin ortaya konulması oldukça önemlidir (14). PMK endometriyum kanserinin en sik semptomudur ve bu vakaların \%1015'inde endometriyum kanseri tespit edilir (15). Servikal kaynaklı patolojilerin tanısı, smear' in tarama metodu olarak kullanılmasıyla daha kolaydır. $\mathrm{Bu}$ nedenle PMK etiyolojisini araştırırken, servikal kaynaklı patolojileri ekarte etmede smear önemli bir araçtır. PMK nedenlerini araştıran çalışmalarda, PMK'nın en sık sebebinin atrofik endometriyum olduğu ve insidansının \%60-80 arasında değiştiği ortaya konulmuştur (16). Diğer sebepler ise hormonal tedavi, akut stres, atrofik vajnit, endometriyal hiperplazi, endometriyal ve servikal karsinomlar ve travma olarak belirtilmektedir (17). PMK'nın etiyolojik tanısı için transvajinal ultrasonografi, endometrial küretaj, tanısal histeroskopi, histeroskopik biyopsi gibi yöntemler kullanılmaktadır (18). PMK sıklıkla polip, atrofi gibi benign nedenlerle ortaya çıksa da; altta yatan olası bir endometriyum kanseri ve kanser öncüsü hiperplazinin de semptomu olabileceğinden, bu semptomla başvuran hastalarda endometrium kalınlığı ne olursa olsun dilatasyon küretaj (D\&C) ile endometriyal örnekleme yapmanın uygun olacağı düşünülmektedir (19). PMK'lı hastalarda patoloji raporu "yetersiz materyal" gelen hastaları içeren bir çalışmada, bu tanı oranının \%14,6 ile en yüksek 60 yaş üstü kadınlarda olduğu vurgulanmıştır (20). Burada önemli nokta, bu hastaların \%10'unun tekrarlayan incelemelerde uterin malignite ortaya koymasıdır. "Yetersiz materyal" tanı sıklığını azaltabilmek için, özellikle ultrasonografide endometriyumu ince saptanan hastalarda, D\&C işleminin deneyimli hekimler tarafindan ve gerekirse ultrasonografi eşliğinde yapılması, bu hastaların materyali incelenirken daha fazla sayıda kesit alınması uygun olacaktır (19).

\section{Vulvar distrofiler}

Vulvar bölgede kaşıntı ile prezente olur. Postmenapozal kadınları rahatsız eden ve çok da az görülmeyen bir durumdur. Yaşlanma ve hipoöstrojenemi derinin bariyer savunma mekanizmalarını bozar. Vulvada mikroorganizmalara ve alerjenlere karşı oluşan immün yanit azalır, mekanik travmaya ve kimyasal irritasyonlara karşı duyarlılık artar (21). Uluslararası Vulvovajinal Hastalıklar Çalışma Derneği (ISSVD International Society for the Study of Vulvar Disease) 2011'de vulvar problemlerin tanı ve tedavisini kolaylaştırmak amacıyla 
bir sınıflandırma yapmıştır ve vulvar intraepitelyal lezyonlar, vulvodini ve vulvar dermatozlar olarak 3 gruba ayırmıştır (22). Vulvar dermatozlar 2006'da histopatolojik tiplerine göre spongiyotik patern (Atopik dermatit, alerjik kontakt dermatit, irritan kontakt dermatit), akantotik patern (psoriasis, liken simpleks kronikus), likenoid patern (liken skleroz, liken planus), dermal skleroz paterni (liken skleroz), vezikülobülloz paten (pemfigoid, lineer Ig A hastalığı), akantolitik patern (Hailey-Hailey hastalığı, Darier hastalığı, papüler genitokrural akantolizis), granülomatöz patern (Crohn hastalığ1, Melkersson-Rosenthal sendromu) ve vaskülopatik patern (Aftöz ülserler, Behçet hastalığı, plazma hücreli vulvit) olarak sınıflandırılmıştır (23). 2011 yılında ise klinik özellikler esas alınarak daha detaylı bir sınıflandırma yapılmıştır. Bunlar ciltle aynı renkte lezyonlar, kırmızı lezyonlar (plak ve yamalar, papül ve nodüller), beyaz lezyonlar (papül ve nodüller), koyu renkli lezyonlar (kahverengi, siyah, mavi ve gri), blister lezyonlar (büller, püstüller ve püstüller), erozyon ve ülserler ve ödem (yaygın genital şişlik) olarak sinıflandırılmıştır (24).

\section{Vulvovajinal atrofi}

$\mathrm{Bu}$ durum kadın hayatının herhangi bir döneminde görülebilse de en çok hipoöstrojenik durumdan dolayı postmenapozal dönemde karşımıza çıkar. Laktasyon ve meme kanseri tedavisinde kullanılan bazı ilaçlar da östrojen azalmasına sebep olur. Premenapozal kadınlarda $\% 23,4$ oranında görülmesine karşın postmenapozal dönemde bu oran \%61,5'e çıkar (25). İlk semptom ilişki sırasında kuruluk olarak karşımıza çıkarken sürekli kuruluk hissi, epiteldeki incelmeye bağlı olarak kaşıntı, şişme ve vulvuvajinal ağrı da görülebilir (26). S1k idrar çıkma noktüri, sıkışma tipi inkontinans da atrofiye bağlı görülürken, stres inkontinans atrofiden etkilenmez (27). Tedavide, sıvı bazlı jel veya lubrikantlar disparoniyi önlemek için kullanılabilirken, östrojen içeren vajinal krem, tablet ve halkalar da kullanılabilmektedir. Vitamin E ve kalsitriolün oral alınmasının da tedaviye katkı sağladığını gösteren çalışmalar mevcuttur (28). Bunun yanı sıra düşük doz lokal östrojen içeren ilaçlarla ilgili çalışmalar devam etmektedir (29).

\section{Pelvik organ prolapsusu ve üriner inkontinans}

Postmenapozal kadınların \%41'inde mevcuttur. Yaşlanmayla birlikte pelvik taban kaslarının gevşemesine bağlı olarak uterin prolapsus, sistosel, rektosel veya enterosel görülebilir. Bunun yanı sıra yaş, kronik kabızlık, doğum ve gebelik, sigara, kronik öksürüğe yol açan nedenler de pelvik relaksasyona katkıda bulunur. Onarılmadığı takdirde erozyonlar sistosele bağlı üriner retansiyon, enterosele bağlı ileus görülebilir. Operasyon öncesi topikal österojen kullanımının, nüks oranlarını azaltmadığı bildirilmiştir. Cerrahi tedavi mümkün olmayan hastalara ise pesser ve kegel egzersizleri önerilir (30).

Üriner inkontinans pelvik taban kasları, mesane, üretral sfinkter, aracı sinirler veya beyindeki işeme merkezinin fonksiyon bozukluğu sonucu gelişir. Bunlara hastanın bilişsel durumu, ek medikal hastalıkları ve kullandığ ilaçlar da katkıda bulunur (31). Ülkemizde geriatrik kadınların \%49'unda urge ve stres inkontinans saptandığ belirtilmiştir (6). Doğum yapma, kronik öksürük ve obezite ile risk artmaktadır. İdrar yolu infeksiyonu, pelvik organ prolapsusu, inme gibi nörolojik hastalıklar ve poliüriye sebep olan metabolik hastalıklar da risk faktörü oluşturmaktadır. Urge inkontinans daha sık görülmektedir. Mesane kas aşırı aktivitesi patolojiye katkıda bulunur. Kegel egzersizi, daha sık idrara çıkma gibi davranış değişiklikleri ve antikolinerjik ilaçlar tedaviye yardımcı olur. Stres üriner inkontinans ise üretral sfinkterde zayıflık, üretra açısındaki bozukluk sebebiyle karın içi basıncı artıran durumlarda idrar kaçırmadır. Östrojen eksikliği de inkontinansı artıran bir durumdur. Kronik öksürük, pelvik taban kas zayıflığı, multiparite risk faktörleri arasında sayılabilir. Geriatrik hastalarda komorbidite ve çoklu ilaç kullanımı olasılığından dolayı üriner inkontinansa tanı koymak özellik arz eder. Deliryum, idrar yolu infeksiyonu gibi akut durumlar dışlanmalıdır. Bu nedenle tanı ve tedavide multidisipliner bir yaklaşım benimsenmelidir. Davranışsal tedaviler medikal tedavilerin yanında sunulmalıdır ve endike olan hastalarda cerrahi yaklaşım söz konusu olabilir (32).

\section{Osteoporoz}

Kemik kaybı 40 ve 50'li yaşlarda başlar ve yaşam boyu devam eder. Erişilen maksimum kemik kütlesi büyük oranda genetik faktörler ile bir miktar diyet ve fiziksel aktivite ilişkilidir. Yaşlılığa bağlı osteoporozda artan kemik rezorpsiyonunu formasyon aktivitesi karşılayamamaktadır. $\quad 80^{\prime}$ li yaşlarda kadınlar \%40, erkekler ise \%25 kemik kaybına uğramış olmaktadırlar (33). Yılmaz ve arkadaşlarının (34) yaptığı çalışmada osteroporoz sıklığı \%11,8 olarak bulunmuş olup yaş ortalaması 60,6 olarak saptanmıştır. Osteoporoz sadece kemik mineral yoğunluğu değerlerini tedavi etme meselesi değildir, osteoporotik kırıklara bağlı akut ve uzun dönem sekelleri kontrol altına almaktır. Günümüzde çok iyi biliniyor ki kemik zayıflığına bağlı kırıklardan dolayı oluşan morbidite, ağrı ve mali giderlerin yanı sıra kırıklara bağlı artmış bir mortalite riski de söz konusudur ve günümüzdeki antirezorptif tedaviler bu riski azaltmaktadır (35).

\section{SONUÇ}

Demografik yapının zaman içerisinde değişmesi yaşlı kadınların jinekolojik bakımına daha fazla eğilme ihtiyacı oluşturmuştur. Altmış beş yaş üstü kadınların jinekolojik problemleri hayat kalitesini veya hijyeni olumsuz etkileyen durumlardan, ciddi mortalite sebebi olabilen malignitelere kadar geniş bir spektrum içinde yer almaktadır. Hastanın birinci basamaktaki hekimler ve jinekologlar tarafından kapsamlı bir biçimde değerlendirilmesi toplumumuzun temel taşlarını oluşturan bu kesimin hastalıklarının erken tanı ve tedavisinde önemli yer tutmaktadır.

\section{KAYNAKLAR}

1. Projections of the population of the United States: 1977 to 2050. Current Population Reports, Series P25, Report No 601. United States: U.S. Government Printing Office; 1993.

2. Berger NA, Savvides P, Koroukian SM, Kahana EF, Deimling GT, Rose JH, et al. Cancer in the elderly. Trans Am Clin Climatol Assoc. 2006; 117:147-56.

3. Howlader N, Noone AM, Krapcho M, Neyman N, Aminou R, Waldron W, et al. SEER Cancer Statistics 
Review, 1975-2009 (Vintage 2009 Populations). Bethesda, MD: National Cancer Institute. Available from: https://seer.cancer.gov/archive/csr/1975_2008/.

4. Lee NK, Fleming GF. Treatment of advanced stage and recurrent endometrial cancer in elderly women. In: Lichtman SM, Audisio RA, editors. Management of Gynecological Cancers in Older Women. London: Springer-Verlag; 2013. p. 257-75.

5. Cancer.org [Internet]. Atlanta: American Cancer Society Inc.; 2013 [Cited: Aug 2018]. Available from: https//www.cancer.org/research/cancer-factsstatistics/all-cancer-facts-figure/2013.html.

6. Duman N, Elbaş N. 65 yaş ve üstündeki kadınların kadın sağlığına yönelik sorunlarının ve etkileyen faktörlerin belirlenmesi. Türk Geriatri Dergisi. 2009; 12(2): 62-71.

7. Berkman S. İleri Evre Endometrium Kanserinde Cerrahi. Ayhan A, Dursun P, Gültekin M, Taşkıran Ç, editörler. Jinekolojik Onkoloji. İstanbul: Güneş Tıp Kitabevi; 2013. s. 417-27.

8. Ayhan A, Başaran M. Endometrium Kanseri. Beksaç MS, editör. Jinekoloji; Üreme Endokrinolojisi \& İnfertilite ve Jinekolojik Onkoloji. İstanbul: Medical Network; 2006. s. 1385-402.

9. Özsaran Z. Endometrium kanserinde radyoterapikemoterapinin rolü: Randomize çalışmalar eşliğinde değerlendirme. Türk Jinekolojik Onkoloji Dergisi. 2013; 4(2): 95-100.

10. Kutsal Y, Eyigör S. Klinisyen gözüyle yaşlılık döneminde sık görülen hastalıklar. Aslan D, Ertem M, editörler. Yaşlı sağlığı sorunlar ve çözümler. Ankara: Palme Yayıncılık; 2012. s. 48-59.

11. Perkins K, King M. Geriatric gynecology. Emerg Med Clin N Am. 2012; 30(4): 1007-19.

12. Yüce K, Dursun P. Adneksiyal Kitle ve Erken Ovaryan Kanser. Ayhan A, çeviri editör. Klinik Jinekolojik Onkoloji. 6. Baskı. Ankara: Güneş Kitabevi; 2003. s. 259-88.

13. Scully RE. Tumors of the ovary, maldeveloped gonads, fallopian tube and broad ligament. In: Young RH, Clement PB, editors. Atlas of tumor pathology. Washington, DC: Armed Forces Institute of Pathology; 1998. p. 51-79.

14. Salman MC, Bozdag G, Dogan S, Yuce K. Role of postmenopausal bleeding pattern and women's age in the prediction of endometrial cancer. Aust N Z J Obstet Gynaecol. 2013; 53(5): 484-8.

15. Epstein E, Valentin L. Managing women with postmenopausal bleeding. Best Pract Res Clin Obstet Gynaecol. 2004; 18(1): 125-43.

16. Fortier KJ. Postmenopausal bleeding and the endometrium. Clin Obstet Gynecol. 1986; 29(2): 4405.

17. Stiles M, Redmer J, Paddock E, Schrager S. Gynecologic issues in geriatric women. Journal of Women's Health. 2012; 21(1): 4-9.

18. Yumru E, Bozkurt M, Çaylan Ö. Postmenopozal kanamalı vakalarda transvajinal ultrasonografi, tanısal histeroskopi ve histeroskopi sonrası biyopsinin değerlendirilmesi. Uludağ Üniversitesi Tıp Fakültesi Dergisi. 2004; 7(4): 237-40.
19. Tepe NB, Bozdağ Z, Özcan HÇ. Postmenapozal kanamanın yaygın nedenleri: Tek merkez 5 yıllık deneyim. Smyrna Tıp Dergisi. 2017; 2(2):10-5.

20. Kandil D, Yang XF, Stockl T, Liu Y. Clinical outcomes of patients with insufficient sample from endometrial biopsy or curettage. Int J Gynecol Pathol. 2014; 33(5): 500-6.

21. Summers PR, Hunn J. Unique dermatologic aspects of the postmenopausal vulva. Clin Obstet Gynecol. 2007; 50(3): 745-51.

22. Hoang MP, Reuter J, Papalas JA, V Edwards L, Selim MA. Vulvar inflammatory dermatoses: An update and review. Am J Dermatopathol. 2014; 36(9): 689-704.

23. Lynch PJ, Moyal-Barracco M, Bogliatto F, Micheletti L, Scurry J. 2006 ISSVD classification of vulvar dermatoses: Pathologic subsets and their clinical correlates. J Reprod Med. 2007; 52(1): 3-9.

24. Lynch PJ, Moyal-Barracco M, Scurry J, Stockdale C. 2011 ISSVD terminology and classification of vulvar dermatological disorders: An approach to clinical diagnosis. J Low Genit Tract Dis. 2012; 16(4): 33944.

25. Crandall C, Petersen L, Ganz P, Greendale GA. Association of breast cancer and its therapy with menopause-related symptoms. Menopause. 2004; 11(5): 519-30.

26. Pandit L, Ouslander JG. Postmenopausal vaginal atrophy and atrophic vaginitis. Am J Med Sci. 1997; 314(4): 228-31.

27. Sultana CJ, Walters MD. Estrogen and urinary incontinence in women. Maturitas. 1994; 20(2-3): 129-38.

28. Yildirim B, Kaleli B, Düzcan E, Topuz O. The effects of postmenopausal vitamin $\mathrm{D}$ treatment on vaginal atrophy. Maturitas. 2004; 49(4): 334-7.

29. Maire B, Mac Bride, MBBCH. Vulvovaginal atrophy. Mayo Clin Proc. 2010; 85(1): 87-94.

30. Miller KL, Baraldi CA. Geriatric gynecology: Promoting health and avoiding harm. Am J Obstet Gynecol. 2012; 207(5): 355-67.

31. Miller K, Stenchever M, Richter H, Granieri E, Andrews W. Geriatric Gynecology. New Frontiers in Geriatrics Research: An Agenda for Surgical and Related Medical Specialties. U.S.A: American Geriatric Society; 2004. p. 201-11.

32. Ínci K, Ergen A. Yaşlilarda üriner inkontinans ve farmakolojik tedavisi. Türk Geriatri Dergisi. 2009; 13(1): 59-66.

33. Gökçe Kutsal Y, Çakmakçı M, Ünal S, editörler. Geriatri. Ankara: Medico Graphics Ajans ve Matbaas1; 1997.

34. Yılmaz M, Başbuğ A, Kaya AE, Çağlar M, Özkara A, Sungur MA ve ark. Osteoporoz Sıklığı ve Tarama Programı Başlangıç Yaşının Belirlenmesi: Düzce Üniversitesi Araştırma ve Uygulama Hastanesi Örneklemi. Konuralp Tip Dergisi. 2017; 9(1): 30-4.

35. Papaioannou A, Morin S, Cheung AM, Atkinson S, Brown JP, Feldman S, et al. 2010 clinical practice guidelines for the diagnosis and management of osteoporosis in Canada: Summary. CMAJ. 2010; 182(17): 1864-73. 